DOI: 10.17707/AgricultForest.61.3.18

\begin{abstract}
Mohtasham MOHAMMADI, Peyman SHARIFI, Rahmatollah KARIMIZADEH, Jabbar ALT JAFARBY, Hasan KHANZADEH, Tahmaseb HOSSEINPOUR, Mohammad Mahi POURSIABIDI, Mozafar ROUSTAII, Maghsood HASSANPOUR HOSNI and Pedram MOHAMMADI ${ }^{1}$
\end{abstract}

\title{
STABILITY OF GRAIN YIELD OF DURUM WHEAT GENOTYPES BY AMMI MODEL
}

\section{SUMMARY}

Quick seed germination and stand establishment are significant factors to lentil This study was performed to determine the yield performances of 20 durum wheat genotypes across five sites in warm dryland areas of Iran, during 20042006 growing seasons. The experimental design was a randomized complete block design with four replications. The combined analysis of variance indicated that effects of environments, genotypes and genotype $\times$ environment (GE) interactions were significant, suggesting differential responses of the genotypes to environments and the need of stability analysis. Analysis of variance for AMMI (additive main effects and multiplicative interactions) model revealed the first four interaction principal components (IPC 1, IPC 2, IPC 3, IPC 4) were highly significant by Gollob's F-test and accounted for $78.32 \%$ of GE interaction. The genotypes have high variation around the mean yield (3358.68 $\mathrm{kg}$ ha-1). According to IPC1, genotypes G17, G3, G1 and G8 were the most stable genotypes. Based on EV4 parameter, genotypes G17, G8, G12, and G18 and according to EV1, genotypes G4, G6, G19, G7 and G20 were the most stable genotypes. Genotypes G10, G9, G4, G14, G11, G6 and G18 based on SIPC4 parameter and genotypes G8, G1, G12, G18 and G17 based on ASV parameter were the most stable genotypes. MASV indicated that G17, G12, G8, G18, G1 and G3 were most stable genotypes. Overall based on the all AMMI parameters, genotypes G3, G8, G1, G12, G17 and G18 were the most stable genotypes which had relatively high mean yield and can be used as superior genotypes in relation with the warm dryland environments.

Keywords: Multi-environment trial, Principal component analysis, genotype $\times$ environment interactions, Yield

\footnotetext{
1 Mohtasham Mohammadi (Corresponding author: mohtashammohammadi@yahoo.com), Rahmatollah Karimizadeh: Dryland Agricultural Research Institute. Gachsaran station.P.O.Box 178. Iran., IRAN Peyman Sharifi, Department of Agronomy and Plant Breeding, Rasht Branch, Islamic Azad University, Rasht, IRAN, Jabbar Alt Jafarby, Hasan Khanzadeh, Tahmaseb Hosseinpour, Mohammad Mahdi Poursiabidi: Seed and Plant Improvement Institute. Mozafar Roustaii, Maghsood Hassanpour Hosni Dryland Agricultural Research Institute, Maragheh station. Pedram Mohammadi, Wheat breeder.IRAN

Note: The authors declare that they have no conflicts of interest. Authorship Form signed online.
} 


\section{INTRODUCTION}

Durum wheat (Tritium turgidum L. subsp. durum (Desf.) Husn.) is a tetraploid species with two diploid genomes AA and BB. It is characterized by possessing grains showing a high degree of virtuousness, relatively high endosperm hardness and being amber in color (El-Khayat et al. 2003). It has a hardest tissue than bread wheat (T. aestivum L.). Durum wheat is the important wheat for producing the best kinds of pasta because of its hard dense texture and grain with high protein and gluten particles. Iran has had an important durum breeding program in recent years, supported by the International Centre for Agricultural Research in the Dry Areas (ICARDA) (Mohammadi e al., 2010), because is a species of great economical interest owing to the nutritional quality of its grain, as well as its high grain yield (Sabaghnia e al., 2012a).

In most of the plant breeding programs, GE interaction effects are of special interest for identifying the most stable genotypes, mega-environments and other adaptation targets. Various methods for yield stability analysis are based on different stability concepts and can be classified accordingly (Flores et al., 1998). Information regarding to crop stability is applicable for selection of genotypes with constant yield across environments. Many of researchers have been reported to depict the responses of genotypes to the different condition of environments for simultaneous selection of yield and stability. Each of these techniques put to use statistical parameters to estimate stability of genotypes to variation in environments. Linear regression approach is used widely for identifying of high yielding and stable genotypes (Alberts, 2004). The additive main effect and multiplicative interaction (AMMI) method is an approach for evaluation of genotypes stability under different environments. The AMMI method merges principal components analysis and analysis of variance into an integrated approach and can be used to analysis of the multi-location experiments (Zobel et al., 1988). The AMMI analysis is effective because it provides agronomically meaningful interpretation of data (Gauch, 1992). The AMMI model is utilized for three main purposes (Gauch, 1988; Crossa et al., 1990): (i) to suitable in the initial statistical analyses of yield experiments, (ii) to summarize the relationships between genotypes and environments (GE) and (iii) to applicable for understanding complex genotypes $\times$ environment interaction effects. AMMI analysis has been applied extensively with great success to interpret genotype $\times$ environment interaction in wheat (Petrovic et al., 2009; Petrovic et al., 2010; Mahmoodi et al., 2011; Oikeh et al., 2004; Mohammadi et al., 2013).

There are several AMMI parameters. The AMMI stability value (ASV) has many similarities with the other AMMI stability parameters which calculated from the first two IPCs scores (Sabaghnia et al., 2012b), However, this stability parameter and its modified parameter (MASV) have several priority to other AMMI stability parameters. Sabaghnia et al. (2008) reported ASV as a good dynamic criteria stability for detecting stable genotypes. Karimizadeh et al. (2012) were also revealed that ASV and MASV was as repeatable parameters and they were proposed that researcher use ASV and MASV parameters for 
evaluating adaptability and stability of genotypes or cultivar because these parameters had high significant correlated with grain yield and also they are repeatable in single year, pair years and triple years. The other reason of priority of these two AMMI parameters is because of its benefit dynamic concept of stability and they could be useful for simultaneous selection of yield and stability. In the other word, ASV and MASV parameters of AMMI model was a reliable statistic to describe GE interaction and simultaneous selection of yield and stability (Adugna and Labuschange, 2003).

The objective of this study is to determine high-yielding and stable durum wheat genotypes, with experiments carried out in fifteen locations..

\section{Experimental data}

\section{MATERIAL AND METHODS}

Twenty durum wheat genotypes, including 18 experimental lines selected from the durum wheat joint project of Iran/ICARDA and two local checks (Seimareh and Koohdasht) were evaluated during three cropping seasons (2004 2006) at five research sites, representative of major durum wheat rainfed and warm winter growing areas of Iran. A list of durum wheat genotypes are given in Table 1. A further description of the used genotypes is given in Table 1.

Table 1. Code, pedigree, and origin of 20 durum wheat genotypes.

\begin{tabular}{|c|c|c|}
\hline Code & Pedigree/Name & source \\
\hline G1 & E90040/MFOWL13 & ICARDA \\
\hline G2 & SRN1/LARU/3/YAV /FGO//ROH/4/LICAN & ICARDA \\
\hline G3 & TANTLO//CREX/ALLA/3TANTLO & ICARDA \\
\hline G4 5 ZEGZAG/ALTAR84//DIPPER & ICARDA \\
\hline G6 & $31-19-2-2$ & Iran \\
\hline G7 & $18-18-1-4$ & Iran \\
\hline G8 & $43-25-2-4$ & Iran \\
\hline G9 & Arislahn-4 & ICARDA \\
\hline G10 & Lgt3/4/Bcr/3/Chi//Gta/Stk & ICARDA \\
\hline G11 & Bcr//Memo/goo & ICARDA \\
\hline G12 & D68-1-93A-1A//Ruff/Fg/3/Mtjtl-5/4/Lahn & ICARDA \\
\hline G13 & Terbo $167-3$ & ICARDA \\
\hline G14 & Bcr//fg/snbipe/3/Gdovz 578/swan//Ddra2 & ICARDA \\
\hline G15 & Fadda-98 & ICARDA \\
\hline G16 & Villemur/3/Lahn//gs/stk/4/Dra2/Bcr & ICARDA \\
\hline G17 & Terbo 197-4 & ICARDA \\
\hline G18 & Stj3//Bcr/LKS4 & ICARDA \\
\hline G19 & Koohdasht (Check) & Iran \\
\hline G20 & Seimareh (Check) & Iran \\
\hline
\end{tabular}


The locations used are: Ghachsaran in the south of Iran; Moghan in the northwest of Iran; Gonbad in the north of Iran; Khoram abad and Ilam in west of Iran. The altitude of testing sites varies from 45 to $1125 \mathrm{~m}$. More descriptions of the experimental sites are given in Table 2 .

Table 2. Name, latitude, longitude, altitude, precipitation and soil texture classes of different testing locations

\begin{tabular}{|c|c|c|c|c|c|c|c|c|c|c|}
\hline \multirow[b]{2}{*}{ Locations } & \multirow[b]{2}{*}{ Code } & \multirow[b]{2}{*}{ Year } & \multirow[b]{2}{*}{ Coordinates } & \multirow[b]{2}{*}{$\begin{array}{l}\text { Altitude } \\
\text { (m) }\end{array}$} & \multirow[b]{2}{*}{$\begin{array}{l}\text { Rainfall } \\
(\mathrm{mm}) \mathrm{a}\end{array}$} & \multicolumn{3}{|c|}{ Temperature b } & \multirow[b]{2}{*}{$\begin{array}{l}\text { Soil } \\
\text { type }\end{array}$} & \multirow[b]{2}{*}{$\begin{array}{l}\text { Climate } \\
\text { c }\end{array}$} \\
\hline & & & & & & Max & Min & $\begin{array}{l}\text { Annual } \\
\text { average }\end{array}$ & & \\
\hline \multirow{3}{*}{ Gachsaran } & E1 & 2004 & \multirow{3}{*}{$\begin{array}{l}50 \text { o 46' N; } \\
50 \text { o 46' E }\end{array}$} & \multirow{3}{*}{710} & 515.2 & 47.8 & -0.6 & 18.9 & \multirow{3}{*}{$\begin{array}{l}\text { Silty- } \\
\text { clay- } \\
\text { loam }\end{array}$} & \multirow{3}{*}{ HSA d } \\
\hline & E6 & 2005 & & & 570.6 & 44.6 & -2.6 & 19.9 & & \\
\hline & E11 & 2006 & & & 511.2 & 45.0 & -1.6 & 18.6 & & \\
\hline \multirow{3}{*}{ Khoramabad } & E2 & 2004 & \multirow{3}{*}{$\begin{array}{l}33 \text { o } 29^{\prime} \mathrm{N} \\
48 \mathrm{o} 22^{\prime} \mathrm{E}\end{array}$} & \multirow{3}{*}{1,125} & 482.9 & 39.0 & -7.0 & 13.4 & \multirow{3}{*}{$\begin{array}{l}\text { Silty- } \\
\text { clay- } \\
\text { loam }\end{array}$} & \multirow{3}{*}{ MSR } \\
\hline & E7 & 2005 & & & 438.3 & 41.0 & -6.0 & 14.1 & & \\
\hline & E12 & 2006 & & & 658.1 & 40.0 & -6.6 & 12.6 & & \\
\hline \multirow{3}{*}{ Gonbad } & E3 & 2004 & \multirow{3}{*}{$\begin{array}{l}37 \text { o } 15^{\prime} \mathrm{N} ; \\
55 \text { o } 10^{\prime} \mathrm{E}\end{array}$} & \multirow{3}{*}{45} & 700.6 & 41.0 & -3.0 & 15.3 & \multirow{3}{*}{$\begin{array}{l}\text { Silty- } \\
\text { clay- } \\
\text { loam }\end{array}$} & \multirow{3}{*}{ MSR } \\
\hline & E8 & 2005 & & & 605.4 & 40.0 & -2.0 & 15.5 & & \\
\hline & E13 & 2006 & & & 456.8 & 40.4 & -3.6 & 15.7 & & \\
\hline \multirow{3}{*}{ Ilam } & E4 & 2004 & \multirow{3}{*}{$\begin{array}{l}330 \text { 3 } 8^{\prime} \mathrm{N} \\
460 \text {; }\end{array}$} & \multirow{3}{*}{973} & 591.2 & 40.4 & -2.8 & 12.78 & \multirow{3}{*}{$\begin{array}{l}\text { Clay- } \\
\text { loam }\end{array}$} & \multirow{3}{*}{ HSA } \\
\hline & E9 & 2005 & & & 574.5 & 42.0 & -0.4 & 17.2 & & \\
\hline & \begin{tabular}{|l|} 
E14 \\
\end{tabular} & 2006 & & & \begin{tabular}{|l|}
470.3 \\
\end{tabular} & 41.0 & -2.4 & 13.9 & & \\
\hline \multirow{3}{*}{ Moghan } & E5 & 2004 & \multirow{3}{*}{$\begin{array}{l}380 \text { 44' N; } \\
47 \text { o } 01^{\prime} \text { E }\end{array}$} & \multirow{3}{*}{100} & 256.7 & 35.0 & -5.2 & 11.7 & \multirow{3}{*}{$\begin{array}{l}\text { Clay- } \\
\text { loam }\end{array}$} & \multirow{3}{*}{ MSR } \\
\hline & E10 & 2005 & & & 182.8 & 36.4 & -4.8 & 15.1 & & \\
\hline & E15 & 2006 & & & 173.7 & 37.0 & -6.0 & 11.8 & & \\
\hline
\end{tabular}

a* Precipitation from October to June.

$\mathrm{b} * *$ Temperature includes months form October to June.

c According to Koppen classification system. The Koppen climate classification is one of the most widely used climate classification systems. It was developed by Wladimir Koppen, a Russian climatologist, around 1900 (with several further modifications by Köppen himself, notably in 1918 and 1936). It is based on the concept that native vegetation is the best expression of climate; thus, climate zone boundaries have been selected with vegetation distribution in mind. It combines average annual and monthly temperatures and precipitation, and the seasonality of precipitation (McKnight and Darrel 2000).

d HSA: Hot and Semi-Arid ; MSR: Mediterranean with Spring Rains

The genotypes were grown in a randomized complete block design with four replications at each site. Plot size was $7.35 \mathrm{~m}^{2}, 7 \mathrm{~m}$ long, 6 rows, and 17.5 $\mathrm{cm}$ between rows. Where an area of $6.3 \mathrm{~m}^{2}$ was harvested to estimate grain per plot and then converted to $\mathrm{kg} \mathrm{ha}^{-1}$.

\section{Statistical analysis}

The grain yield data were subjected to combined analysis of variance and AMMI analysis which is a combination of analysis of variance and multiplication effect analysis. Briefly, analysis of variance is conducted to determine the effect of environment (E), genotype (G) and GE interaction. Subsequently, multiplication effect analysis is used to partition GE deviations into different interaction principal component axes (IPC), which can be tested for statistical 
significance through ANOVA. The IRRISTAT software was used for combined analysis of variance and AMMI analysis.

The eigenvalue (EV) stability parameter of AMMI (Zobel, 1994) was calculated according to this expression:

$$
E V=\sum_{n=1}^{N} \gamma_{i n}^{2} / n
$$

In this formula, $\gamma_{\text {in }}$ is the genotype eigenvector for axis $\mathrm{n}$ and $\mathrm{N}$ is the number of IPC that were retained in the AMMI procedure via different F-tests.

The SIPC (Sum of IPC scores) (Sneller et al., 1997) parameter is expressed as:

$$
S I P C=\sum_{n=1}^{N} \lambda_{n}^{0.5} \gamma_{i n}
$$

Where, $\lambda_{n}$ is the eigenvalue of the IPC analysis axis $n$. In this equation $\mathrm{N}=1$ for SIPC1; for SIPCF, $\mathrm{N}$ was the number of IPC that were retained in the AMMI model.

The AMMI stability value (ASV) as described by Purchase (1997) was calculated as follows:

$$
A S V=\sqrt{\left[\frac{S S I P C 1}{S S I P C 2}(I P C 1)^{2}\right]+(I P C 2)^{2}}
$$

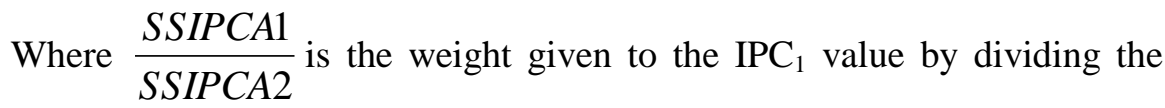
IPC1 sum of squares by the IPC2 sum of squares. The larger the IPC score, either negative or positive, the more specifically adapted a genotype is to certain environments. Smaller ASV scores indicate a more stable genotype across environments.

For effective interpretation of GE interactions via AMMI model a new parameter as modified AMMI's stability value (MASV) is introduced as below formula (Adugna and Labuschange, 2002):

$$
M A S V=\sqrt{\sum_{n=1}^{N-1}\left(\frac{S S I P C_{n}}{S S I P C_{n+1}}\right)\left(I P C_{n}\right)^{2}+\left(I P C_{n+1}\right)^{2}}
$$

In this modified AMMI stability parameter, all significant IPCs were used. All analyses were performed using the statistical package Genstat release 12.0 (Genstat, 2010) and SAS release 9.1 (SAS, 2004).

\section{RESULTS AND DISCUSSION}

Homogeneity of variance tests indicated homogenous error variance for grain yield in the fifteen environments and allowed for a combined analysis across environments. The combined analysis of variance (Table 3 ) indicated that the main effects of random environments and fix genotypes were significant for 
grain yield that exhibiting the presence of variability in genotypes and diversity of growing conditions at different environments.

Table 3. Combined and AMMI analysis of variance and contributions of the first four principal components for grain yield of 20 durum wheat genotypes in 15 environments.

\begin{tabular}{|c|c|c|c|}
\hline Source & df & Mean Squares & $\begin{array}{c}\% \text { of } \mathrm{G} \times \mathrm{E} \\
\text { Interaction } \mathrm{SS}\end{array}$ \\
\hline Environment & 14 & 91725091** & \\
\hline $\begin{array}{l}\text { Replication within } \\
\text { Environment }\end{array}$ & 45 & 398875 & \\
\hline Genotype & 19 & $4510540 * *$ & \\
\hline $\begin{array}{l}\text { Genotype } \times \\
\text { Environment }\end{array}$ & 266 & $678590 * *$ & \\
\hline AMMI 1 & 32 & $475792 . * *$ & 33.74 \\
\hline AMMI 2 & 30 & $285737 . * *$ & 19.00 \\
\hline AMMI 3 & 28 & $249503 . * *$ & 15.48 \\
\hline AMMI 4 & 26 & $175256 . * *$ & 10.10 \\
\hline GXE RESIDUAL & 150 & $65201.6^{\mathrm{ns}}$ & 21.68 \\
\hline Error & 855 & 162628 & \\
\hline $\begin{array}{l}\text { Coefficient of } \\
\text { Variation }(\mathrm{CV})\end{array}$ & & 12 & \\
\hline
\end{tabular}

ns, not significant, ${ }^{*}$ and $* *$ significant at the 0.05 and 0.01 probability level, respectively.

AMMI: additive main effect and multiplicative interaction

The significant effects of genotype $\times$ environment interaction reflected to the differential response of genotypes in various environments. This demonstrated that GE interaction was highly significant and had remarkable effect on genotypic performance in different environments. As GEI was significant, it was possible to proceed and calculate stability (Lin et al., 1986). The GEI was accounted for $11 \%$ of TSS and was greater than the G effect. Grain yield is the net effect of $\mathrm{G}, \mathrm{E}$ and $\mathrm{GE}$ interaction, and although $\mathrm{E}$ is responsible for about $75 \%$ of the total variability, only $\mathrm{G}$ and GE interaction are relevant to the evaluation of genotypes in multi-environment trials (Yan and Kang, 2002). The magnitude of the GEI sum of squares was about two times larger than that for genotypes. It is very common for mega-environmental trials (METs) data to embody a mixture of crossover and non-crossover types of GEI (Ahmadi et al., 2012). Cooper et al. (1995) mentioned that the large magnitude of GE interaction causes more dissimilarity in the genetic systems that are controlling the physiological processes that are conferring yield stability in different environments. The relative contributions of GE interaction effects for grain yield in this study were similar to findings in other studies (Bertero et al., 2004; Sabaghnia et al., 2006; 2013). Therefore, GE interaction makes it difficult to select the best performing and most stable genotypes. The large E and GEI in this study suggest the possible existence of different mega-environments with 
different top-yielding genotypes (Yan and Kang, 2002). This result revealed that there was a differential yield performance among genotypes across testing environments due to the presence of GEI. The presence of GEI complicates the selection process as GEI reduces the usefulness of genotypes by confounding their yield performance through minimizing the association between genotypic and phenotypic values (Crossa, 1990).

The AMMI analysis of variance revealed the IPC 1, IPC 2, IPC 3, IPC 4 axes were highly significant $(\mathrm{P}<0.01)$ by the F-test that was proposed by Gollob (1966). IPC 1, IPC 2, IPC 3 and IPC 4 axes explained 33.74\%, 19.00, 15.48 and $10.10 \%$ of the total GEI, respectively. The four IPCs retained by Gollob's F-test accounted for $78.32 \%$ of GE interaction. The mean squares for IPC 1 and IPC 2 cumulatively contributed to $52.74 \%$ of the total GEI. However, if the number of significant IPCs were more than two IPCs, the visual interpretation of GE interaction through biplot is not valid due to low explanation of first two IPCs (Gauch, 2006). The AMMI model in this study indicated that there was a more complex interaction of GE and it could not facilitate graphical visualization of the genotypes in low dimensions and so it is essential to use an alternative procedure to interpretation of GE interaction using AMMI parameters (Sabaghnia et al., 2008).

Mean yield performance along with mean rank of genotypes across environments is presented in Table 4. The genotypes have high variation around the mean yield $\left(3358.68 \mathrm{~kg} \mathrm{ha}^{-1}\right)$. The range of grain yield was from $2794.05 \mathrm{~kg}$ $\mathrm{ha}^{-1}$ (G5) to $3809.95 \mathrm{~kg} \mathrm{ha}^{-1}$ (G10). Thirteen genotypes produced higher grain yield than the grand mean. In general, G10, G9 and G18 give the best yield performance, while G5, G6 and G7 had the lowest mean yield performance across environments.

Tables 4 display the first four principal component axes scores for genotypes and mean of four IPCs. The IPC scores of a genotype in the AMMI analysis are an indication of the stability or adaptation over environments. The greater IPC scores, negative or positive, (as it is a relative value), the more specific adapted is a genotype to certain environments. The more IPC scores approximate to zero, the more stable or adapted the genotype is over all the environments (Purchase, 2000). The lowest IPC1 was observed for genotypes G17 and G3 followed by G1, G8, G20, G6, G9 and G12, respectively (Table 5). Between these genotypes, G17, G3, G1, G20, G9 and G12 had higher mean yield than grand mean. The highest IPC1 was belonged to G5 followed by G4, G7 and G11, respectively. Overall, according to mean of IPC1-4, G1, G12, G8, G17 and G18 had the lowest values and were recognized as the most stable genotypes. IPC scores of genotype and environment also took both positive and negative values (Table 4). Consequently, a genotype that has large positive IPC score with some of environments, most have negative interaction with the other environments. Thus, these scores presented a disproportionate genotype response (Yan and Hunt, 2001), which was the major source of variation for any crossover (qualitative) interaction. This disproportionate genotype response is referred to as 
crossover GEI for convenience. Diversely, scores with the some sign or near zero represent a non - crossover (quantitative) GEI or a proportionate genotype response (Mohammadi and Amri, 2008).

Table 4. Average yield and First four Interaction Principal Component Analysis parameters for 20 durum wheat genotypes.

\begin{tabular}{|c|c|c|c|c|c|c|c|}
\hline Genotypes & Yield & Rank & IPC1 & IPC2 & IPC3 & IPC4 & $\begin{array}{c}\text { Average } \\
\text { IPC1-4 }\end{array}$ \\
\hline G1 & 3461.07 & 8 & 2.54 & -3.397 & 8.73 & -0.72 & 3.27 \\
\hline G2 & 3497.36 & 7 & -11.77 & 4.812 & 16.98 & -10.87 & 2.36 \\
\hline G3 & 3371.53 & 12 & -2.019 & -11.19 & 3.32 & 5.52 & 2.81 \\
\hline G4 & 3211.39 & 17 & -30.74 & 7.08 & -20.67 & 10.10 & 4.29 \\
\hline G5 & 2794.05 & 20 & 32.17 & -10.76 & -12.54 & 11.31 & 2.06 \\
\hline G6 & 2814.5 & 19 & 4.154 & 25.75 & -31.17 & -7.73 & 6.60 \\
\hline G7 & 2838.33 & 18 & 28.01 & 2.082 & 1.90 & 16.71 & 8.60 \\
\hline G8 & 3337.64 & 14 & 3.228 & -1.148 & -4.47 & 5.15 & 4.37 \\
\hline G9 & 3706.5 & 2 & -4.346 & -21.74 & -3.12 & -11.54 & 9.87 \\
\hline G10 & 3809.95 & 1 & -8.462 & -19.6 & -10.78 & -4.93 & 9.49 \\
\hline G11 & 3533.3 & 4 & -15.71 & -1.489 & 2.54 & 0.98 & 10.97 \\
\hline G12 & 3367.37 & 13 & -4.777 & -1.987 & 4.41 & -0.33 & 10.19 \\
\hline G13 & 3510.65 & 6 & 8.819 & 0.3667 & 10.98 & -4.37 & 10.94 \\
\hline G14 & 3405.82 & 11 & 9.981 & -10.17 & -7.74 & -18.57 & 12.16 \\
\hline G15 & 3245.47 & 16 & -10.97 & 8.377 & 9.31 & 11.61 & 11.32 \\
\hline G16 & 3512.48 & 5 & -9.865 & 5.3 & 4.51 & 15.02 & 12.18 \\
\hline G17 & 3419.42 & 10 & -1.501 & -7.797 & 2.79 & -0.51 & 20.35 \\
\hline G18 & 3586.22 & 3 & -5.288 & -2.785 & 4.34 & -4.79 & 11.65 \\
\hline G19 & 3296.51 & 15 & 12.67 & 24.92 & 8.31 & -20.35 & 25.71 \\
\hline G20 & 3454.01 & 9 & 3.878 & 13.36 & 12.40 & 8.31 & 19.45 \\
\hline
\end{tabular}

IPC1- IPC4 are first four interaction principal component environment, respectively,

Table 5 indicates results for stability of different durum wheat genotypes according to several AMMI parameters. According to the EV4 stability statistic, a genotype is considered to be more stable provided that the EV4 is lower. Therefore, G17, G8, G12, and G18 were the most stable genotypes which had relatively high mean yield performance, whereas G4, G19, G6, G2 and G5 were the most unstable genotypes which had relatively low mean yield performance. According to EV1 which benefits only IPC1 scores, genotypes G4, G6, G19, G7 and G20 were the most stable genotypes and based on EV4 (IPC1-IPC2), genotypes G17, G8, G12, and G18 were the most stable genotypes (Table 5). 
Thus, different numbers of IPCs in EV computation results in obtaining relatively different conclusions in identification of the most stable genotypes. It is important to notice that EV1 parameter is based on only $33.74 \%$ of GE interaction variability, while EV4 are based on AMMI models that explain $78.32 \%$ of GE interaction sum of squares. The values of the SIPC4 parameter could be useful in identifying genotypes stability and so G10, G9, G4, G14, G11, G6 and G18 were the most stable genotypes whereas, G7, G20, G19 and G5 were the most unstable genotypes. It is interesting that most of stable genotypes according this parameter had high mean yield except G4 and G6.

Table 5. Values of AMMI stability parameters for 20 durum wheat genotypes.

\begin{tabular}{|c|c|c|c|c|c|}
\hline Genotypes & EV1 & \multicolumn{1}{l|}{ EV4 } & SIPC4 & ASV & MASV \\
\hline G1 & 0.057 & 0.027 & 7.15 & 4.49 & 17.76 \\
\hline G2 & 0.048 & 0.075 & -0.84 & 14.40 & 41.53 \\
\hline G3 & 0.055 & 0.026 & -4.36 & 11.43 & 20.74 \\
\hline G4 & 0.020 & 0.123 & -34.23 & 36.15 & 67.13 \\
\hline G5 & 0.048 & 0.072 & 20.18 & 38.63 & 61.27 \\
\hline G6 & 0.033 & 0.082 & -8.99 & 26.19 & 69.02 \\
\hline G7 & 0.044 & 0.070 & 48.70 & 32.37 & 53.33 \\
\hline G8 & 0.057 & 0.017 & 2.76 & 3.90 & 13.88 \\
\hline G9 & 0.055 & 0.038 & -40.74 & 22.31 & 37.87 \\
\hline G10 & 0.056 & 0.025 & -43.77 & 21.90 & 38.93 \\
\hline G11 & 0.049 & 0.032 & -13.67 & 18.18 & 23.03 \\
\hline G12 & 0.058 & 0.017 & -2.68 & 5.86 & 13.21 \\
\hline G13 & 0.055 & 0.030 & 15.79 & 10.18 & 27.23 \\
\hline G14 & 0.051 & 0.055 & -26.49 & 15.36 & 40.50 \\
\hline G15 & 0.056 & 0.045 & 18.32 & 15.17 & 34.96 \\
\hline G16 & 0.053 & 0.065 & 14.96 & 12.55 & 32.43 \\
\hline G17 & 0.059 & 0.016 & -7.01 & 7.99 & 13.05 \\
\hline G18 & 0.059 & 0.017 & -8.52 & 6.70 & 16.26 \\
\hline G19 & 0.041 & 0.099 & 25.55 & 28.89 & 56.12 \\
\hline G20 & 0.045 & 0.068 & 37.94 & 14.09 & 34.70 \\
\hline ASV:
\end{tabular}

ASV: AMMI stability value, MASV: Modified AMMI stability value, SIPC: Sum of IPC scores, EV: Eigenvectors

The AMMI stability value (ASV) was the other stability parameter. According this stability parameter, a genotype with least ASV score is the most stable. The high interaction of genotypes with environments was also confirmed 
by high ASV and rank, suggesting erratic (unstable) yield across environments. Results of ASV parameter showed genotypes G8, G1, G12, G18 and G17 as the most stable genotypes, respectively. The most unstable genotypes were G5, G4 and G7 (Table 5). Although, ASV parameter was reported to produce a balanced measurement between the two first IPC's (IPC1 and IPC2) scores, but it seems that this parameter is useful when the portion of explained total variation was relatively high (Sabaghnia et al., 2008). It should be noticed that the ASV parameter uses IPC1 and IPC2 scores as well as magnitude of their sum of squares and so is different from the other AMMI parameters which use only genotypic or environmental IPCs scores or their modifications (Sabaghnia et al., 2012c). The PC1 and PC2 variance explanations were low in this study; therefore we used modified AMMI's stability value (MASV) which benefits all four significant IPCs. The results of MASV indicated that genotypes G17, G12, G8, G18, G1 and G3 were most stable which had relatively high mean yield performance, whereas genotypes G6, G4 and G5 were the most unstable genotypes which had relatively low mean yield performance (Table 5). Therefore, MASV parameter introduced some of the high mean yielding genotypes (G17 and G18) as the most stable ones. Therefore, according to our results, AMMI parameters which are computed from four IPCs, were more useful and introduced relatively the high yielding genotypes as the most stable genotypes. Considering the mean ranks of all of the AMMI stability parameters, genotypes G3, G8 and G1 following to genotypes G12, G17 and G18 were the most stable genotypes. All of these stable genotypes, except of G8 had the high mean yield performance over grand mean.

The AMMI model used in the present study indicated a more complex GE interaction which required as many as four IPCs. This phenomenon could be related with the nature of the crop, environmental conditions or diverse genetic background obtained from different sources. Multivariate statistical methods such as AMMI can explore multi-directionality aspects and try to extract more information from GE interaction component. According to Gauch (2006) and Gauch et al. (2008), AMMI procedure has several advantages to the other multivariate statistical methods. They declared that AMMI is superior or equal to GGE and proposed to avoid needless multiplication of methodologies; there is no call for a mix-and- match strategy using both procedures. It seems that simultaneous assessment of four IPCs scores of the AMMI method for durum wheat genotypes facilitates the interpretation of GE interaction and identification of superior genotypes. Plant breeders have used firstly the stability concept for identifying a genotype with constant yield in different environments (static concept) but later simultaneous considering of both mean yield and stability is proposed (dynamic concept). The ASV and MASV benefit dynamic concept of stability and could be useful simultaneous selection of yield and stability (Dehghani et al., 2010). The results of present study are in agreement with Adugna and Labuschagne (2002) who found that the ASV parameter of AMMI model was a reliable statistic to describe GE interaction and simultaneous 
selection of yield and stability. In dynamic concept of stability, it is not needed that the genotypic response to environmental conditions should be equal for all genotypes (Becker and Leon, 1988)..

\section{CONCLUSIONS}

The AMMI model gives a simple measure of yield stability which allows a ranking of genotypes. This model was also as an effective tool in understanding complex GE interactions in multi-environment trials of durum wheat. Also, besides diff erences in crops and regions (climatic conditions, soil properties etc), the observed GE interactions may be partly explained by the structure of the dataset that was considered and by the selection of the genotypes. The interaction of 20 genotypes with 15 environments was best predicted by the first four principal components of genotypes and environments. the AMMI stability parameters helped breeders to have an overall picture in behavior of the genotypes, the environments and GEIs. The results obtained by AMMI analysis indicated that genotypes G1 (E90040/MFOWL13), G8 (Arislahn-4), G12 (D681-93A-1A//Ruff/Fg/3/Mtl-5/4/Lahn), G17 (Terbo 197-4) and G18 (Stj3//Bcr/LKS4) were as the stable genotypes and can be used as superior genotypes in durum wheat breeding for warm dryland areas.

\section{ACKNOWLEDGMENTS}

The authors are grateful for the support provided by Dry Land Agricultural Research Institute of Iran. Sincere gratitude goes to other colleagues in the other Agricultural Research Stations (Khorram-Abad, Moghan and Gonbad) for their technical assistance.

\section{REFERENCES}

Ahmadi, J., Vaezi, B. \& Fotokian, M.H. (2012): Graphical analysis of multi-environment trials for barley yield using AMMI and GGE-biplot under rain-fed conditions. J. Plant Physi. Breed. 2(1), 43-54.

Adugna, W. \& Labuschagne, M.T. (2002): Genotype, environment interactions and phenotypic stability analyses of linseed in Ethiopia. Plant Breed. 121, 66-71.

Adugna, W. \& Labuschagne, M.T. (2003): Parametric and nonparametric measures of phenotypic stability in linseed (Linum usitatissimum L.). Euphytica 129, 211-218.

Alberts, M.J.A. (2004): A comparison of statistical methods to describe genotype $\times$ environment interaction and yield stability in multi-location maize trials. Plant Breeding MSc Thesis, University of the free state Bloemfontein. $100 \mathrm{p}$.

Becker, H.C. \& Léon, J. (1988): Stability analysis in plant breeding. Plant Breed. 101, 123.

Crossa, J., Gauch, H.G. \& Zobel, R.W. (1990): Additive main effects and multiplicative interaction analysis of two international maize cultivar trials. Crop Sci. 30, 493 500 .

Crossa, J. (1990): Statistical analyses of multilocation trials. Advan. Agron. 44: 55-85.

Dehghani, H., Sabaghpour, S.H. \& Ebadi, A. (2010): Study of genotype $\times$ environment interaction for chickpea yield in Iran. Agron. J. 102, 1-8. 
El-Khayat, G.H., Samaan, J. \& Brennan, C.S. (2003): Evaluation of vitreous and starchy Syrian durum (Triticum durum) wheat grains: The effect of amylose content on starch characteristics and flour pasting properties. In Starch/Stärke, 55, 358-365.

Gauch, H.G. (1988): Model selection and validation for yield trials with interaction. Biometrics 44, 705-715.

Gauch, H.G. J. (1992): Statistical Analysis of Regional Yield Trials: AMMI Analysis of Factorial Designs. Elsevier, Amsterdam.

Gauch, H.G. (2006): Statistical analysis of yield trials by AMMI and GGE. Crop Sci. 46, 1488-1500.

Gauch, H.G., Piepho, H.P. \& Annicchiarico, P. (2008): Statistical analysis of yield trials by AMMI and GGE: Further considerations. Crop Sci. 48, 866-889.

Genstat, (2010): Genstat for Windows. 12th ed. VSN Int., Hemel Hempstead, UK.

Gollob, H.F. (1968): A statistical model which combines features of factor analytic and analysis of variance techniques. Psychometrika 33, 73-115.

Karimizadeh, R., Mohammadi, M., Shefazadeh, M.K., Mahmoodi, A.A., Rostami, B. \& Karimpour, F. (2012): Relationship among and repeatability of ten stability indices for grain yield of food lentil genotypes in Iran. Turkish J. Field Crop. 17(1), 51-61.

Lin, C.S., Binns, M.R. \& Lefkovitch, L.P. (1986): Stability analysis: Where do we stand? Crop Sci. 26, 894- 900.

Mahmoodi, N., Yaghotipoor, A. \& Farshadfar, E. (2011): AMMI stability value and simultaneous estimation of yield and yield stability in bread wheat (Triticum aestivum L.). Australian J. Crop Sci. 5(13), 1837-1844.

Mohammadi, M. (2012): Parameters of additive main effects and multiplicative interaction model for interpreting of genotype $\times$ environment interaction. J. Food, Agric. \& Environ. 10 (1), 777-781.

Mohammadi, R. \& Amri, A. (2008): Comparison of parametric and non-parametric methods for selecting stable and adapted durum wheat genotypes in variable environments. Euphytica. 159, 419-432.

Mohammadi, R., Mohammadi, M., Karimizadeh, R. \& Amri, A. (2010): Analysis of genotype-by-environment interaction for grain yield of rainfed durum wheat genotypes in warm winter areas of Iran. J. Crop Sci. Biot. 13, 267-274.

Mohammadi, M., Karimizadeh, R. \& Hosseinipour, T. (2013): Parameters of AMMI model for yield stability analysis in durum wheat. Agric. Con. Sci. . 78, 119-124.

Oikeh, S.O., Menki A., Maziya-Dixon, B., Welch, R.M., Glahn, R.P. \& Gauchjr, G. (2004): Environmental stability of iron and zinc concentrations ingrain of elite early-maturing tropical maize genotypes grown under field conditions. J. Agric. Sci. 142, 543-551.

Petrovic, S., Dimitrijevic, M., Belic, M., Banjac, B. \& Vukosavljev. M. (2009): Spike stability parameters in wheat grown on solonetz soil. Genetika, 41(2), 199 -205.

Petrovic, S., Dimitrijevic, M., Belic, M., Banjac, B., Boskovic, J., Zecevic, V. \& Pejic, B. (2010): The variation of yield components in wheat (Triticum aestivum L.) in response to stressful growing conditions of alkaline soil. Genetika, 4(3), 545-555.

Purchase, J.L. (1997): Parametric analysis to describe $G \times E$ interaction and yield stability in winter wheat. Ph.D. thesis. Dep. of Agronomy, Faculty of Agriculture, Univ. of the Orange Free State, Bloemfontein, South Africa.

Purchase, J.L., Hatting, H. \& Vandeventer, C.S. (2000): Genotype $\times$ environment interaction of winter wheat (Triticum aestivum L.) in South Africa: П. Stability analysis of yield performance. South African J. Plant Soil 17:101-107. 
SAS Institute, 2004. SAS/STAT user's guide. v. 9.1. SAS Inst., Cary, NC.

Sabaghnia, N., Sabaghpour, S.H. \& Dehghani, H. (2008): The use of an AMMI model and its parameters to analyze yield stability in multi-environment trials. J. Agric. Sci. 146, 571-581.

Sabaghnia, N., Karimizadeh, R. \& Mohammadi, M. (2012): Model selection in additive main effect and multiplicative interaction model in durum wheat. Genetika. 44(2), 325-339.

Sabaghnia, N., Karimizadeh, R. \& Mohammadi, M. (2012): Grain yield stability analysis of lentil genotypes by additive main effects and multiplicative interactions model. YYU. J. AGR. SCI. 22(3), 155-164.

Sabaghnia, N., Mohammadi, M. \& Karimizadeh, R. (2013): Parameters of AMMI model for yield stability analysis in durum wheat. Agric. Cons. Sci. 78, 119-124.

Sabaghnia, N., Mohammadi, M. \& Karimizadeh, R. (2012c): The evaluation of Genotype $\times$ environment interaction of durum wheat's yield using of the AMMI model. Agriculture and Forestry 55, 5-21.

Sneller, C.H., Kilgore-Norquest, L. \& Dombek, D. (1997): Repeatability of yield stability statistics in soybean. Crop Sci. 37, 383-390.

Yan, W., Hunt, L. A. (2001). Interpretation of genotype $\times$ environment interaction for winter wheat yield in Ontario. Crop Science, 41: 19-25.

Yan, W., \& Kang, M.S. (2002): GGE biplot analysis: A graphical tool for breeders, geneticists, and agronomists. CRC Press, Boca Raton, FL. pp 271.

Zobel, R.W. (1994): Stress resistance and root systems. p. 80-99. In Proc. Of the Workshop on Adaptation of Plants to Soil Stress. 1-4 Aug. 1993. INTSORMIL Publ. 94-2. Inst. of Agriculture and Natural Resources, Univ. of Nebraska, Lincoln.

Zobel, R.W., Wright, M.J. \& Gauch, H.G. (1988): Statistical analysis of a yield trial. Agron. J. 80, 388-393. 